\title{
THE CHALLENGE OF CRAFTING RULES TO CHANGE OPEN ACCESS RESOURCES INTO MANAGED RESOURCES
}

\author{
by \\ Elinor Ostrom \\ Workshop in Political Theory and Policy Analysis \\ Indiana University, Bloomington \\ Center for the Study of Institutional Diversity \\ Arizona State University \\ $\odot 2007$ by author
}

Paper presented at the International Economic Association roundtable on the Sustainability of Economic Growth, Beijing, China, July 13-14, 2007.

\begin{abstract}
Designing rules to govern common-pool resources is presented in many environmental treatises as resting on two core assumptions that: (1) resource users are norm-free maximizers of immediate gains who will not cooperate to overcome the commons dilemmas they face, and (2) government officials, on the other hand, have the information and motivation to design efficient and effective rules to sustain the use of common-pool resources over the long run. In this paper I review evidence related to these assumptions that leads one to doubt their validity when applied to smaller to medium-sized common-pool resources where users have opportunities to communicate with one another and learn how to engage in reciprocal behavior. Findings from carefully controlled laboratory experiments are summarized that challenge the first assumption and leads one to have to assume that humans are fallible and boundedly rational. Depending on the context of the situation, individuals may add normative payoffs (positive and negative) to their preference function.

The complexity of using rules as tools to change the structure of commons dilemmas is then discussed, drawing on extensive research on rules in field settings. Viewing all policies as experiments with a probability of failure, I will explore the size and structure of the rule space that individuals have used in previous efforts to govern commons. The final section discusses the likely performance of a series of completely independent resource governance systems or a fully integrated one - ending with a discussion of the importance of polycentric governance systems.
\end{abstract}

\section{Workshop in Political Theory and Policy Analysis}

\author{
Indiana University, 513 North Park, Bloomington, IN 47408-3895 USA
}

phone: 812.855.0441 / fax: 812.855.3150 / workshop@indiana.edu / http://www.indiana.edu/ workshop 


\section{THE CHALLENGE OF CRAFTING RULES TO CHANGE OPEN ACCESS RESOURCES INTO MANAGED RESOURCES}

by

\section{Elinor Ostrom}

\section{Garrett Hardin's Model is Correct but Highly Limited in Applicability}

Garrett Hardin's (1968), "tragedy of the commons" is one of the most cited articles in environment science and is assigned repeatedly to undergraduate students in Environmental Science curricula. Whenever scholars and policy discuss the problems of overuse and degradation of natural resources whether they be fisheries, forests, irrigation systems or the atmosphere, Hardin's article is apt to be relied upon heavily. Why has this almost metaphoric article captured so much attention? First of all, Hardin presents an extraordinarily clear and vivid picture of a pasture "open to all." Second, his assumptions about the motivation of resource harvesters are consistent with the assumptions about market participants that have proved powerful in deriving propositions regarding highly competitive markets. Viewing resource users as trapped in a tragedy of their own making is consistent with many textbooks on resource economics and the predictions derived from non-cooperative game theory for finitely repeated dilemmas (E. Ostrom et al 1994). External authorities are presumably needed to impose rules and regulations on local users since they will not do this themselves. The "scientific management of natural resources" that is frequently taught to future regulators of natural resources presents fisheries, forests, and water resources as relatively homogeneous units that are closely interrelated across a vast domain. Fish and wildlife species are presented as if they always migrate over a large range. Irrigation systems are interlinked along watersheds of major river systems. This approach, as it has been applied to fisheries management, is described by Acheson et al (1998:391-92).

For those trained in scientific management, it is also an anathema to manage a species over only part of its range. From the view of fisheries scientists and administrators, it is not rational to protect a species in one zone only to have it migrate into another area where it can be taken by other people due to a difference in regulations. As a result, the units to be managed range along hundreds of miles of coast and can only be managed by central governments with jurisdiction over the entire area. Lobsters, for example, extend from Newfoundland to the Carolinas; swordfish migrate from the Caribbean to Newfoundland and Iceland. From the point of view of the National Marine Fisheries Service, it makes sense to have a set of uniform regulations for the entire US coast rather than one for each state. (see Sherman \& Laughlin 1992)

The belief in the capability of government analysts to design optimal rules to govern and manage common-pool resources for a large domain is shared by many academics. When common-pool resources are viewed as having a homogeneous structure and as being interlinked, simple models are developed for how they work. It is then presumed that officials -- acting in the public interest -- are capable of devising uniform and effective rules for an entire region. The textbooks indicate that all that is needed is reliable, statistical information on key variables for an entire region - ignoring the huge variance that may be hidden in even reliable data. Then, it is frequently presumed that one can determine the optimal harvesting level, divide this harvesting level into quotas, assign quotas to users, and allow them to buy and sell these transferable quotas. Prescriptions calling for central governments to impose uniform regulations over most natural resources are thus consistent with important bodies of theoretical work. Groups who have actually organized themselves to govern resources are frequently invisible to those who cannot imagine organization without rules and regulations issued by a central authority (see, for example, Lansing 1991, Lansing \& Kremer 1994). 
Extensive research does not support uniform prescriptions for an entire region to be imposed by external authorities. Hayes and Ostrom (2005) analyzed data from 163 forests located in 12 countries, of which 76 were government-owned forests that were legally designated as protected forests and 87 were public, private, and community-owned forested lands used for diverse purposes (see also Hayes 2006). No statistical difference was found between the vegetation densities related to officially designated, government-owned protected areas as contrasted with other property regimes. E. Ostrom and Nagendra (2006) and Gibson, et al (2005) present evidence that whether rules are monitored by users is more important to achieve the sustainability of forest resources than the formal ownership status. A large number of field studies have found that local groups of resource users have crafted a diversity of institutional arrangements for coping with common-pool resources where they have not been prevented from doing so by central authorities (McCay \& Acheson 1987, Fortmann \& Bruce 1988, Berkes 1989, 2007; Meinzin-Dick, 2007; Netting 1993, Bromley et al 1992, Tang 1992, Blomquist 1992; Lam, 1998). These empirical studies document successful self-organized resource governance systems in diverse sectors in all parts of the world as well as cases where self-organized systems have not been successful.

We can now firmly conclude in light of extensive empirical evidence that overuse and destruction of common-pool resources is not a determinant and inescapable outcome when multiple users face a commons dilemma. Some of the key conditions of a resource, and of the users of a resource, have been identified that are conducive to local users self-organizing to find solutions to commons dilemmas (see E. Ostrom 2001; Baland \& Platteau 1996). The broad design principles that characterize robust selforganized resource governance systems that have resolved commons dilemmas for long periods of time have been identified (E. Ostrom 1990; 2005) and found basically sound by other scholars (Morrow \& Hull 1996; Trawick 2001; Bardhan 2000; Weinstein 2000; Guillet 1992a, 1992b; Gupta and Tiwari 2002.

A disjuncture exists between currently accepted theoretical and resultant policy recommendations related to commons and evidence from the field (Berkes et al 1989) and the lab (Ostrom, Gardner and Walker, 1994). Empirical findings challenge two of the most important theoretical foundations of contemporary analysis. One foundation is the model of the human actor that is used. Resource users are explicitly thought of as norm-free, short-term, maximizers of immediate gains who will not cooperate, unless coerced by external authorities, to overcome the perverse incentives of social dilemmas in order to increase their own and others' long-term benefits. Inconsistently, government officials are depicted as capable of seeking the more general public interest and analyzing long-term patterns so as to design optimal policies. A second foundational belief for many policy analysts is that it is relatively simple to design rules to change the incentives of participants. Analysts view most resources in a particular sector as relatively similar and sufficiently inter-related that they need to be governed by the same set of rules.

In this paper, I propose to show that these foundational assumptions are wrong and a poor foundation for public policy recommendations. To do this, I will first need to define what is meant by a commonpool resource. To address the adequacy of the model of the human actor used, I then summarize the findings from a series of carefully controlled laboratory experiments of appropriation dilemmas. Given that predictions based on the model of a norm-free, myopic, and maximizing individual are not supported, except when individuals act anonymously and cannot discuss their joint problem, I then discuss the presentation of a closely related but alternative conception of human behavior-applicable to resource users and government officials alike. Humans are viewed as fallible, boundedly rational, and norm using. In complex settings, no one is able to do a complete analysis before actions are taken, but individuals learn from mistakes and are able to craft tools-including rules-to improve the structure of the repetitive situations they face.

Then, I explore the complexity of using rules as tools to change the structure of commons dilemmas. First I describe the seven clusters of rules that affect the components of any action situation, and then describe the specific rules that are used in field settings by resource users and government agencies. An 
examination of the types of rules used in the field yields several important findings. First, the number of rules actually used in field settings is far greater than generally recognized. Second, the type of rules is

also different. Boundary rules tend to include as co-appropriators of a resource those who are more likely to be trustworthy because they live permanently nearby and have a long-term stake in keeping a resource sustainable. Choice rules define rights and duties that are easy to understand, directly related to sustaining the biophysical structure of the research, and easy to monitor and enforce. Some rules recommended in the policy literature are not found among the rules used by self-organized systems.

Given the complexity of the process of designing rules to regulate the use of common-pool resources, I argue that all policy proposals must be considered as experiments. No one can possibly know whether a proposed change in rules is among the more optimal rule changes or even whether a rule change will lead to an improvement. All policy experiments have a positive probability of failing. Then I discuss how the parallel efforts by a large number of local resource users to search out and find local rule configurations may find better rule combinations over the long term while top-down design processes are more limited in their capacities to search and find appropriate rules. All forms of decision making have limits. Thus, we need to understand the limits of fully decentralized, independent resource governance systems and the importance of building polycentric governance systems with considerable overlap to combine the strengths of parallel search and design processes with the strengths of larger systems in conflict resolution, acquisition of scientific knowledge, monitoring the performance of local systems, and the regulation of common-pool resources that are more global in their scope. The resulting polycentric governance systems are also not directed by a single center bit rather a form of complex adaptive systems.

\section{What is a Common Pool Resource?}

A common-pool resource is a natural or man-made resource from which it is difficult to exclude or limit users once the resource is provided by nature or produced by humans (E. Ostrom et al 1994). What one person consumes from removes resource units from what is available to others. Thus, the trees or fish harvested by one user are no longer available for others. Commons share the difficulty of excluding beneficiaries with public goods, while the subtractability of the resource units is shared with private goods. In order to provide a focus, I will primarily examine renewable natural resources as exemplars of common-pool resources, but the theoretical arguments are relevant to man-made common-pool resources as well.

When the resource units (e.g., the fish, trees, or water) produced by a common-pool resource have a high value and institutional constraints do not restrict the way these units are appropriated, individuals face strong incentives to appropriate more and more resource units leading eventually to congestion, overuse, and even the destruction of the resource itself. Because of the difficulty of excluding beneficiaries, the free-rider problem is a potential threat to any efforts to reduce harvesting and improve the long-term outcomes achieved from the use of the common-pool resources. If some individuals are cooperative and do not harvest as many units, the benefits so generated are shared with others whether the others cut back on their harvesting or not. Some individuals are likely to free ride on the costly actions of others unless ways are found to reduce free riding as an attractive strategy. Once some users free ride, others are likely to follow suit and over-harvesting may soon be the outcome.

Consequently, one of the important problems facing the joint users of a common-pool resource is known as the "appropriation problem" given the potential incentives in all jointly used common-pool resources for individuals to appropriate more resource units when acting independently than they would if they could find some way of coordinating their appropriation activities. Joint users of a common-pool resource often face many other problems including assignment problems, technological externality problems, provision problems, and maintenance problems (E. Ostrom et al 1994, E. Ostrom \& Walker 
1997). And, the specific character of each of these problems differs substantially from one resource to the next. Here, I will focus primarily on appropriation problems since they are what most analysts associate with "the tragedy of the commons."

\section{$\underline{\text { A Baseline Appropriation Situation }}{ }^{1}$}

Let us start with a static, "institution-free," baseline situation that is as simple as feasible without losing crucial aspects of the problems that real appropriators face in the field. This will let us understand the outcomes predicted and achieved in such a baseline situation and the processes involved in changing the structure by changing rules affecting it. This institution-free, static, baseline situation is composed of:

1. A set of $n$ symmetric appropriators who are interested in withdrawing resource units from a common-pool resource.

2. No differentiation exists in the positions these appropriators hold relevant to the common-pool resource. In other words, there is only one position of appropriator.

3. Appropriators must decide how to allocate their time and effort in each time period. We can think of these appropriators as being "endowed" with a set of assets, e, that they are free to allocate during each time period to two activities. Appropriators must decide, for example, for each time period between spending time trying to harvest resource units from the common-pool resource or to use time in their next best opportunity, such as working in a local factory. To simplify the problem, let us assume that all appropriators have the same endowment, face the same labor market, and can earn a fixed wage for any time they allocate to working for a factory.

4. The actions they take, affect the amount of resource units that can be appropriated from the common-pool resource or wages earned in the labor market.

5. Transformation functions map the actions of all of the appropriators given the biophysical structure of the resource itself onto outcomes. While these functions are frequently stochastic in field settings and affected by many variables in addition to the actions of individuals, let us assume here determinant functions. The wage function simply multiplies the amount of time allocated to it by whatever is the standard wage. The appropriation function is a concave function, $\mathrm{F}$, that depends on the number of assets, $\mathrm{x}_{\mathrm{i}}$, allocated to appropriation from the common-pool resource. Initially, the sum of individuals' actions, $\sum \mathrm{x}_{\mathrm{i}}$, generates better outcomes than the safe investment in wage labor. If the appropriators decide to allocate a sufficiently large number of their available assets, the outcome they receive is less than their best alternative. Such a function is specified in many resource economics textbooks based on Gordon (1954) and Scott (1955).

6. Re information, let us assume that appropriators know the shape of the transformation function and know that they are symmetric in assets and opportunities. Information about outcomes is generated after each decision round is completed.

7. Payoff rules specify the value of the wage rate and the value of the resource units obtained from the common-pool resource. As analysis in E. Ostrom, et al 1994; the payoff to an appropriator is given by:

\footnotetext{
${ }^{1}$ Sections of this paper draw on Elinor Ostrom 1999. "Coping with Tragedies of the Commons.” Annual Review of Political Science 2:493-535.
} 


$$
\begin{array}{ll}
\text { we } & \text { if } x_{i}=0 \\
w\left(e-x_{i}\right)+\left(x_{i} / \sum x_{i}\right) F\left(\sum x_{i}\right) & \text { if } x_{i}>0 .
\end{array}
$$

Basically, if appropriators put all of the assets into the available wage labor, they receive a known return equal to the amount of their endowment times the wage rate. If appropriators put some of their assets into wage labor and some into the common-pool resource, they get part of their return from wages and the rest from their proportional investment in the common-pool resources times the total output of the commonpool resource as determined by function $F$.

\section{Assumptions about Actors}

To explain and predict the outcome of any situation, one needs to specify four key characteristics about the actors who are participating in the situation: (1) the type of preferences held, (2) how information is processed, (3) the formula or heuristic used for making decisions, and (4) the resources brought to the situation. The theory of complete rationality uses the assumptions that (1) individuals have a complete and transitive ordering of preferences over all outcomes that is monotonically related to only their own returns, (2) all relevant information generated by the situation is used in making decisions, (3) actors maximize their own expected returns, and (4) all needed resources to act in this situation are possessed. The theory of norm-free, complete rationality has proved to be extremely useful in a diversity of circumstances where the institutional arrangements reduce the number of options and complexity of the situation and reward those who maximize expected returns to self and punish those who do not. When such situations are completely specified, clear predictions of equilibrium outcomes can be derived. Behavior in experimental laboratories and in the field closely approximates the predicted equilibrium in simple action situations where selection pressures retain those who maximize their own expected returns and thin out those who do not.

The theory of norm-free, complete rationality is also useful in a variety of other situations to enable the analyst to undertake a full analysis and predict equilibrium outcomes. If behavior deviates from the predicted outcomes, one has a clear benchmark for knowing how far behavior deviates from that predicted by this theory. We will thus initially use the theory of norm-free, complete rationality and the theory of finitely repeated games to predict what the outcome would be if a set of experimental subjects were to face a fully specified baseline appropriation situation as outlined above. We will later modify this set of assumptions in light of the evidence obtained in the experimental laboratory (and supplemented by field studies).

\section{Predicted Outcomes for a Common-Pool Resource in the Laboratory}

Laboratory experiments provide an opportunity to observe how humans behave in situations that are very simple when compared to field settings, but nonetheless, characterize essential common elements of relevant field situations. In the laboratory experiments conducted at Indiana University, we thought it crucial to examine behavior in an appropriation situation with a non-linear transformation function and a sufficient number of players that knowledge of outcomes did not automatically provide information about each player's actions. In this paper, I can only briefly discuss the results of these experiments. All procedures and specifications are thoroughly documented in Ostrom et al (1994) and in journal articles cited therein. In the baseline experiments, we utilized the following equation for the transformation function, $F$.

$$
23\left(\sum \mathrm{x}_{\mathrm{i}}\right)-25\left(\sum \mathrm{x}_{\mathrm{i}}\right)^{2}
$$


Eight subjects participated in all experiments discussed in this paper and each subject was assigned 25 tokens as their endowment in each round of play. Their outside opportunity was valued at \$.05 per token. They earned $\$ .01$ on each outcome unit they received from investing tokens in the common-pool resource. Subjects were informed that they would participate in an experiment that would last no more than two hours, but the number of rounds in each experiment varied between 20 and 30 rounds. The situation was described as involving a choice between investing in either of two markets having the structure as specified above. In addition to being told the payoff function specifically, subjects were provided with look-up tables that eased their task of determining outcomes depending on their own and others' decisions. All experiments reported on in this paper involved subjects who had prior experience in similar experiments.

With these specifications, the predicted outcome for a finitely repeated game where subjects are not discounting the future is for each subject to invest 8 tokens in the CPR for a total of 64 tokens (the Nash Equilibrium). The players could, however, earn more if the total number of tokens invested was 36 tokens, rather than 64 tokens, in the common-pool resource. This optimal level of investment would earn each subject $\$ .83$ per round. The baseline experiment is a clear example of a commons dilemma.

\section{Outcomes of a N-Person Repeated Appropriations Dilemma}

As documented in Ostrom et al (1994), subjects interacting in baseline experiments substantially overinvested as predicted. On average, subjects received -3 percent of optimum (Ostrom et al 1994:116). However, at the individual level, subjects rarely invested 8 tokens, which is the predicted Nash equilibrium. Instead, there was an unpredicted and strong pulsing pattern in all experiments. Individuals appear to increase their investments in the common-pool resource until there is a strong reduction in yield, at which time they tend to reduce their investments leading to an increase in yields. The pattern is repeated over time. No game-theoretical explanation exists for the pulsing pattern.

Subjects explained that they were using several rules of thumb or heuristics in response to postexperiment questioning. One of the heuristics was to invest more in the common-pool resource whenever the rate of return on the previous round was above $\$ .05$ (what they could earn in their next best alternative) and less if the return was below $\$ .05$. Equilibrium is really never reached at the individual level. Thus, "each player is continually having to revise his or her response to the current 'anticipated' situation. This strategic turbulence on top of an already complex task increases the chances that a player may not attempt a best-response approach to the task but rather invoke simple rules of thumb. .." (E. Ostrom et al 1994:121-22).

These laboratory experiments have been replicated by other researchers (Rocco \& Warglein 1995; Cardenas 2001; Cardenas, et al 2000; Casari \& Plott, 2003) with similar results.

\section{Structural Changes in the Lab}

In addition to the baseline experiments, we have explored how changes in the rules affect outcomes. In the lab Rule changes are operationalized by the set of instructions given to subjects and in the procedures adopted within the experiment. The first structural change we used is an information rule change. Instead of forbidding all communication among subjects, as in the baseline experiments, subjects were now authorized to communicate with one another in a group setting before returning to their terminals to make their own private decisions. This rule change gave subjects an opportunity for "cheap talk." In cheap talk conditions, agreements made by subjects are not enforced by an external authority. Cheap talk is viewed within the context of non-cooperative game theory as irrelevant. The same outcome is predicted as in the baseline experiment. 
In a second series of experiments, we changed the authority and payoff rules to allow subjects to sanction one another at a cost to themselves. Using this rule change enables subjects to produce a benefit for all at a cost to the themselves. The game-theoretic prediction is that no one will choose the costly sanctioning option. Third, we changed the authority rule to allow subjects to covenant with one another to determine their investment levels and to adopt a sanctioning system if they wished. Again, the predicted outcome is the same. In all three of these changed appropriation experiments, however, subjects demonstrate their willingness and ability to search out and adopt better outcomes than those predicted.

\section{Face-to-Face Communication}

In the repeated communication experiments, subjects made ten rounds of decisions in the context of the baseline appropriation game. An announcement then told them they would have an open group discussion before each of the continuing rounds of the experiment. The subjects left their terminals and sat in a group facing one another. After each discussion, they returned to their terminals and entered their anonymous decisions. Subjects used face-to-face communication to discuss together what strategy would gain them the best outcomes and to agree on what everyone should invest in the subsequent rounds. After each decision round, they were informed what their aggregate investments had been, but not the decisions of individual players. Thus, they learned whether total investments were greater than their agreement. While in many rounds, subjects kept their promises, some defections did occur. If promises were not kept, subjects used this information to castigate the unknown participant who had not kept to their agreement.

Subjects in the 25-token baseline experiments had received total returns that were slightly below zero, while in the communication experiments, they obtained on average 62 percent of the maximum available returns (with variation across experiments). The defection rate was 13 percent. Our conclusion in completing an analysis of these experiments was:

Communication discussions went well beyond discovering what investments would generate maximum yields. A striking aspect of the discussion rounds was how rapidly subjects, who had not had an opportunity to establish a well-defined community with strong internal norms, were able to devise their own agreements and verbal punishments for those who broke those agreements. . . . In many cases, statements like "some scumbucket is investing more than we agreed upon" were a sufficient reproach to change defectors' behavior. (E. Ostrom et al 1994:160)

The process of internalizing norms regarding the importance of keeping promises is evidenced by several of their behaviors. Simply promising to cut back on their investments in the common-pool resource led most subjects to change their investment pattern. Secondly, subjects were indignant about evidence of investment levels higher than that promised and expressed their anger openly. Third, those who broke their promise tended to revert to the promised level after hearing the verbal tongue-lashing of their colleagues.

\section{Sanctioning Experiments}

Participants in many smaller CPRs in the field are usually able to communicate with one another on a face-to-face basis either in formally constituted meetings or at social gatherings. In most field settings, however, participants also devised a variety of formal or informal ways of sanctioning one another if rules are broken. Engaging in costly monitoring and sanctioning behavior is, however, not consistent with the theory of norm-free, complete rationality (Elster 1989:40-41). Thus, it was important to ascertain whether subjects in a controlled setting would actually pay in order to assess a financial punishment on the behavior of other participants. The short answer to this question is yes. 
In all of the sanctioning experiments, subjects played ten rounds of the baseline game modified so that the individual contributions in each round were reported as well as the total outcomes. Subjects were then told that in the subsequent rounds they would have an opportunity to pay a fee in order to impose a fine on the payoffs received by another player. The fees ranged in diverse experiments from \$.05 to \$.20 and the fines from $\$ .10$ to $\$ .80$. Much more sanctioning occurred in these experiments than the zero level predicted. Subjects reacted both to the cost of sanctioning and to the fee/fine relationships. They sanctioned more when the cost of sanctioning was less and when the ratio of the fine to the fee was higher.

Sanctioning was primarily directed at those who invested more in the common pool resource, but a few sanctions appear to be directed by those who had been fined in a form of "blind revenge" against those whose investments were lower than others and were thus suspected of having sanctioned them. Since we first report the results of our sanctioning experiments (Ostrom, et al.,1992), many other scholars have designed experiments where subjects were given the option of sanctioning others and have consistently found higher levels of sanctioning than predicted by theory (Carpenter, et al., 2004; Fehr \& Gächter, 2000; Anderson \& Putterman 2005).

In this set of experiments, subjects were able to increase their returns modestly to 39 percent of maximum, but when the costs of fees and fines were subtracted from the total, these gains are wiped out. When subjects were given a single opportunity to communicate prior to the implementation of sanctioning capabilities, they were able to gain an average of 85 percent of the maximum payoffs (69 percent when the costs of the fees and fines were subtracted).

\section{Covenanting Experiments}

In self-organized field settings, the opportunity to punish those who free ride is much more likely to emerge from an endogenous process of crafting their own rules, including the punishments that should be imposed if these rules are broken. Spending time and effort designing rules creates a public good for all of those involved and is thus a second-level dilemma. Non-cooperative game theory predicts that participants will not undertake such efforts. This is the theoretical foundation for the policy advice that rules must be imposed on participants by external authorities who then assume responsibility for monitoring and enforcing these rules. Since self-organized rules are found in many local common-pool resource situations, it does appear that participants frequently do design their own rules contrary to the theoretical prediction. Few scholars are able to witness these processes, however.

Subjects experienced with baseline and sanctioning experiments were recalled and given an opportunity to have a "constitutional convention" in the laboratory. They could decide whether or not they would like to have access to a sanctioning mechanism like the one described above, how much the fines and fees should be, and on the joint investment strategy that they would like to adopt. Four out of six experimental groups adopted an agreement and specified the number of tokens they would invest and the level of fines to be imposed. The fines determined by the participants ranged in size from $\$ .10$ to $\$ 1.00$. The groups that crafted their own agreements were able to achieve an average of 93 percent of the maximum in the periods after their agreement. And, the defection rate for these experiments was only 4 percent. The two groups that did not agree to their own covenant did not fare as well. They averaged 56 percent of the maximum available returns and faced a defection rate of 42 percent. Consequently, those subjects that used an opportunity to covenant with one another to agree on a joint strategy, choose their own level of fines, received very close to optimal results based entirely on their own promises and their own willingness to monitor and sanction one another when it was occasionally necessary (see Frohlich et al 1987 for similar findings). 


\section{Developing a Theory of Human Behavior Consistent with Evidence from the Lab}

The appropriation experiments briefly summarized above provide the following picture of behavior in $\mathrm{N}$ person, finitely repeated, commons-dilemma situations:

1. When individuals are held apart and unable to communicate on a face-to-face basis, they overuse a common-pool resource.

2. Individuals initially use opportunities for face-to-face discussions to share their understanding of how their actions affect the joint outcomes and arrive at a common understanding of the best joint strategy available to them.

3. Individuals tend to use heuristics in dealing with complex problems and these vary in their capabilities to cope with changing configurations of actions by other participants.

4. Individuals are willing to promise others, whom they assess as being trustworthy, that they will adopt a joint plan of action. Most individuals keep their promises (even in situations where substantial advantage can accrue for breaking the promise).

5. If agreements are broken, individuals become indignant and use verbal chastisements when available. They are also willing to use (and overuse) costly sanctions, but they do not use grim trigger strategies.

6. When given an opportunity to craft their own rules and sanction non-conformance to these rules, many (but not all) groups are willing to do so and then tend to achieve close to optimal results. .

In other words, individuals tend to rely on diverse heuristics in response to complexity. Without communication and agreements on joint strategies, overuse of a common-pool resource is highly likely. On the other hand, individuals are willing to discuss ways of increasing their own and others' payoffs over time. Many are willing to make contingent promises when others are assessed as trustworthy. A substantial number of individuals, but not all, are trustworthy and reciprocate the trust that has been extended. When non-cooperative behavior is discovered, individuals are willing to use retribution in a variety of forms.

Assuming that individuals have the capability to engage in problem solving to increase long-term payoffs, to make promises, to build reputations for trustworthiness, to reciprocate trustworthiness with trust, and to punish those who are not trustworthy, leads to a different policy conclusion than assuming that individuals seek their own short-term, narrow interests even when presented with repeated situations where everyone's joint returns could be substantially increased. Using the latter theory leads to the policy advice that rules to reduce overuse must be devised by external authorities and enforceably imposed on local users. This was the foundation for most policy prescriptions regarding the regulation of commonpool resources during the second half of the last century.

A better foundation is to assume that humans may not be able to analyze all situations fully, but that they will make an effort to solve complex problems by crafting regularized procedures and will be able to draw on inherited capabilities to learn norms of behavior, particularly reciprocity (E. Ostrom 1998, Bendor 1987). A behavioral theory of boundedly rational and norm-using behavior, views all policies as experiments and asks what processes of search and problem solving are more likely to arrive at better experiments. The key problems to be solved are how to ensure that those using a common-pool resource share a similar and relatively accurate view of the problems they need to solve, how to devise rules to which most can contingently agree (Levi 1988), and how to monitor activities sufficiently so that those 
who break agreements through error or succumbing to the continued temptations that exist in all such situations are sanctioned, and thus trust and reciprocity are supported rather than undermined (Bendor \& Mookherjee 1990).

Common-pool dilemmas never fully disappear even in the best operating systems. The temptation to cheat always exists. No amount of monitoring and sanctioning reduces the temptation to cheat entirely. Instead of thinking of overcoming or conquering tragedies of the commons, effective governance systems cope better than others with the on-going need to encourage high levels of trust at the same time as needing to monitor actions and sanction rule infractions.

Presenting this difference in a theoretical perspective based on carefully designed laboratory experiments is the first task that I set out to accomplish. Boundedly rational, local users are potentially capable of changing their own rules, enforcing the rules they agree upon, and learning from experience to design better rules. The next task is to show why multiple, boundedly rational, local users are better at designing rules than a team of boundedly rational officials in a central agency. To do this, we need to draw on research about the type of rules used in the field.

\section{Experimenting with Rules in the Field}

With this change in perspective, we can think of appropriators trying to understand the biophysical structure of a resource they are using and how to affect each other's incentives so as to increase the probability of sustainable and more efficient use over the long term. Instead of being given a set of instructions with the transformation function fully specified - as subjects do in a lab experiment appropriators in the field have to explore and discover the biophysical structure of a particular resource that will differ on key parameters from similar resources in the same region. Further, they have to cope with considerable uncertainty related to the weather, complicated growth patterns of biological systems that may at times be chaotic in nature, and external price fluctuations affecting the costs of inputs and value of outcomes (see Wilson et al 1991, 1994; 2007). In addition to the physical changes that they can make in the resource, the tools they can use to change the structure of the action situations they face consist of seven clusters of rules that directly affect the components of their own action situations. Specifically, the rules they can change affect the working parts of an action situation or a game (E. Ostrom, 2005). They include:

Boundary rules affect the characteristics of the participants.

Position rules differentially affect the capabilities and responsibilities of those in positions.

Choice rules affect the actions that participants in positions may, must, or must not do.

Scope rules affect the outcomes that are allowed, mandated, or forbidden.

Aggregation rules affect how individual actions are transformed into final outcomes.

Information rules affect the kind of information present or absent in a situation.

Payoff rules affect assigned costs and benefits to actions and outcomes.

Given the non-linearity and complexity of action situations in the field, it is rarely easy to predict what effect a change in a particular rule will produce. For example, a change in a boundary rule to restrict the entry of other potential users simultaneously reduces the number of individuals who are tempted to break rules, but it also reduces the number of individuals who monitor what is happening or contribute 
funds toward hiring a guard. Thus, the opportunities for rule breaking may increase. Further, the cost of a rule infraction will be spread over a smaller group of appropriators and thus, the harm to any individual may be greater. Assessing the overall effects of a change in boundary rules is a non-trivial analytical task (for examples, see Weissing \& Ostrom 1991a,b; Acheson \& Gardner 2005). Instead of conducting such a complete analysis, appropriators are more apt to use their past experience in using the resource and with one another to experiment with different rule changes until they find a combination that seems to work in their setting.

To understand the types of tools that appropriators from common-pool resources use somewhat better, let us examine in some detail the kind of boundary, choice, payoff, and position rules found in field settings. These four clusters of rules are the major tools we have repeatedly found that affect the performance of common-pool resource systems. Information, scope, and aggregation rules are utilized to complement changes induced by these four rules.

For the several decades, colleagues at or associated with the Workshop in Political Theory and Policy Analysis at Indiana University have studied a very large number of irrigation systems, forests, inshore fisheries, and groundwater basins, as well as other common-pool resources (see Schlager 1990; Tang 1992; Schlager et al 1994; Lam 1998; Gibson et al 1998; Nagendra et al., 2005; Gautam \& Shivakoti 2005). We have collected an immense archive of original case studies conducted by many different scholars on all sectors in all parts of the world (see the Digital Library of the Commons for extensive citations, http://dlc.dlib.indiana.edu/). Using the IAD framework, multiple research teams have developed structured coding forms to help identify the specific kinds of action situations faced in the field as well as the types of rules that users have evolved over time to try to govern and manage their resource effectively.

\section{Using Boundary Rules}

Policy analysts frequently recommend limiting the number of persons allowed to appropriate from a common-pool resource so that the level of appropriation is reduced or to require users to obtain a license before harvesting. Boundary rules affect the types of participants with whom other participants will interact. If contingent cooperation is perceived to be a possibility, then an important way to enhance the likelihood of using reciprocity norms is to increase the proportion of participants who are well known in a community, have a long-term stake in that community, and would try to build their reputation for trustworthiness in the community. Reducing the number of users but opening the resource to strangers willing to pay a license fee, but who lack a long-term interest in the sustainability of a particular resource, may reduce the level of trust and willingness to use reciprocity and thus increase enforcement costs substantially.

As shown in Table 1, we identified 27 boundary rules described by case-study authors as having been used in at least one common-pool resource somewhere in the world (E. Ostrom et al 1994). While some systems use only a single boundary rule, many use two or three of these rules in combination. Boundary rules can be broadly classified in three general groups defining how individuals gain authority to enter and appropriate resource units from a common-pool resource. The first type of boundary rule relates to an individual's citizenship, residency, or membership in a particular organization. Forestry and fishing user groups frequently require members to have been born in a particular location.

A second broad group of rules relates to individual ascribed or acquired personal characteristics. Other user groups may require that appropriation depends on ethnicity, clan, or caste. A third group of boundary rules relates to the relationship of an individual with the resource itself. Using a particular technology or acquiring appropriation rights through an auction or a lottery are examples of this type of 
rule. About half of the rules relate to the characteristics of the users themselves. The other half involve diverse relationships with the resource.

In a systematic coding of those case studies for which sufficient information existed about rules related to inshore fisheries in many parts of the world, Schlager (1994) coded 33 user groups out of the 44 groups identified as having at least some rules regarding the use of the resource. All 33 groups depended on a combination of 14 different boundary rules (Schlager 1994:258) and none relied on a single boundary rule. Thirty out of 33 groups (91 percent) limited fishing to those individuals who lived in a nearby community, while 13 groups also required membership in a local organization. Consequently, most inshore fisheries organized by the users themselves restrict fishing to those individuals who are well known to each other, have a relatively long-term time horizon, and are connected to one another in multiple ways (see Taylor 1982, Singleton \& Taylor 1992).

After residency, the next most frequent type of rules, used in two-thirds of the organized subgroups, involves the type of technology that a potential fisher must be willing to use. These rules are often criticized by policy analysts, since gear restrictions tend to reduce the "efficiency" of fishing. Used in combination with choice rules that assign fishers using one type of gear to one area of the fishing groups and fishers using another type of gear to a second area, however, these solve conflicts among noncompatible technologies. Many gear restrictions also place a reduced load on the fishery itself and thus help to sustain longer-term use of the resource. They also reduce the cost of monitoring conformance with rules. In addition, other groups used a wide diversity of rules shown in Table 1. The key finding for the argument presented in this paper is that Schlager did not find that any particular boundary rule was correlated with higher performance levels. Schlager did find, however, that the 33 groups who had at least one boundary rule tended to be able to solve common-pool problems more effectively than the 11 groups who had not crafted boundary rules.

In a related study of 43 small- to medium-sized irrigation systems managed by farmers or by government agencies, Tang (1992) found that the variety of rules used in irrigation was smaller than among inshore fisheries. The single most frequently used boundary rule, used in 32 of the 43 systems (74 percent), was that an irrigator must own land in the service area of an irrigation system (Tang 1992:84-85). All of the government-owned and operated irrigation systems relied on this rule and only this rule. Many of the user-organized systems relied on other rules or land ownership combined with other rules. Among the other rules used were ownership of a proportion of the flow of the resource, membership in a local organization, and a per-use fee. Tang (1992:87) found a strong negative relationship between reliance on land as the sole boundary requirement and performance. Over 90 percent of the systems using other boundary rules or a combination of rules including land ownership, were rated positively in the level of maintenance achieved and in the level of rule conformance, while less than 40 percent of those systems relying solely on land ownership were rated at a higher performance level $(\mathrm{p}=.001)$. Many government systems are designed on paper to serve an area larger than they are actually able to serve when in operation, due to a variety of factors including the need to show as many posited beneficiaries as possible to justify the cost of construction (see Palanisami 1982, Repetto 1986; Shivakoti and Ostrom, 2002). After construction, authorized irrigators find water to be very scarce and are unwilling to abide by choice rules or contribute to the maintenance of the system.

The rich diversity of boundary rules used by appropriators in the field appears to be a way of ensuring that the appropriators will be relating to others who live nearby and have a long-term interest in sustaining the productivity of the resource. One way of coping with the commons is thus changing the composition of who uses a common-pool resource to increase the proportion of participants who have a long-term interest, are more likely to use reciprocity, and who can be trusted. Central governments tend to use a smaller set of rules and some of these may open up a resource to strangers without a longer-term commitment to the resource. 


\section{Using Choice Rules}

Choice rules are also a major tool used to regulate common-pool resources. Some rules involve a simple formula. Many forest resources, for example, are closed to all forms of harvesting during one portion of the year and open for extraction by all who meet the boundary rules during an open season. Most choice rules, however, have two components. On Table 2, the eight allocation formulas used in the field are shown in the left column. A fisher might be assigned to a fixed location (a fishing spot) or to a fixed rotational schedule, a member of the founding clan may be authorized to cut timber anywhere in a forest, while an irrigator might be assigned to a fixed percentage of the total water available during a season or to a fixed time slot. In addition to the formula used in an choice rule, most rules required a basis for the assignment. For example, a fisher might be assigned to a fixed location based on a number drawn in a lottery, on the purchase of that spot in an auction, or on the basis of his or her historical use. An irrigator might be assigned to a fixed rotation based on the amount of land owned, the amount of water used historically, or the specific location of the irrigator.

If all bases were combined with all of the formula, there would be 112 different choice rules (8 allocation formulas $\mathrm{x} 14$ bases). A further complication is that the rules for one product may differ from those of another product in the same resource. In regard to forest resources, for example, children may be authorized to pick fruit from any tree located in a forest so long as it is for their own consumption, women may be authorized to collect so many headloads of dead wood for domestic firewood and certain plants for making crafts, while shaman are the only ones authorized to collect medicinal plants from a particular location in a forest (Fortmann \& Bruce 1988). Appropriation rights to fish are frequently related to a specific species. Thus, the exact number of rules that are actually used in the field is difficult to compute since not all bases are used with all formulas, but many rules focus on specific products. A still further complication is that the rules may regularly change over the course of a year depending on resource conditions.

Schlager (1994:259-60) found that all 33 organized subgroups used one of the five basic formulas in their choice rules. Every user group included in her study assigned fishers to fixed locations using a diversity of bases including technology, lottery, or historical use. Thus, spatial demarcations are a critical variable for inshore fisheries. Nine user groups required fishers to limit their harvest to fish that met a specific size requirement, while seven groups allocated fishers to fishing spots using a rotation system and seven other groups only allowed fishing locations to be used during a specific season. Four groups allocated fishing spots for a particular time period (a fishing day or a fishing season).

An important finding-given the puzzles addressed in this paper-is that the authority rule most frequently recommended by policy analysts (see Anderson 1986, 1992; Copes 1986), is not used in any of the coastal fisheries included in Schlager's study. Thus, no attempt was made "by the fishers involved to directly regulate the quantity of fish harvested based on an estimate of the yield. This is particularly surprising given that the most frequently recommended policy prescription made by fishery economists is the use of individual transferable quotas based on estimates on the economically optimal quantity of fish to be harvested over the long run" (Schlager 1994:397). In an independent study of 30 traditional fishery societies, James Wilson and colleagues also noted the surprising absence of quota rules:

All of the rules and practices we found in these 30 societies regulate 'how' fishing is done. That is, they limit the times fish may be caught, the locations where fishing is allowed, the technology permitted, and the stage of the life cycle during which fish may be taken. None of these societies limits the 'amount' of various species that can be caught. Quotas-the single most important concept and tools of scientific management-is conspicuous by its absence. (Acheson et al 1998:397; see Wilson et al 1994) 
Local inshore fishers, when allowed to manage a riparian area, thus use rules that differ substantially from those recommended by advocates of scientific management. Fishers have to know a great deal about the ecology of their inshore region including spawning areas, nursery areas, the migration routes of different species, and seasonable patterns just in order to succeed as fishers. Over time, they learn how "to maintain these critical life-cycle processes with rules controlling technology, fishing locations, and fishing times. Such rules in their view are based on biological reality" (Acheson et al 1998:405).

In the irrigation systems studied by Tang (1992:90-91), three types of choice rules are used most frequently: (1) a fixed time slot is assigned to each irrigator (19 out of the 37 cases for which data is available, and in 10 out of 12 government-owned systems), (2) a fixed order for a rotation system among irrigators (13 cases), and (3) a fixed percentage of the total water available during a period of time (5 cases). Three poorly performing systems with high levels of conflict use no authority rule at all. A variety of bases were used in these rules such as "amount of land held, amount of water needed to cultivate existing crops, number of shares held, location of field, or official discretion" (Tang 1994:233). Farmers also do not use rules that assign a specific quantity of water to irrigators other than in the rare circumstances where they control substantial amounts of water in storage (see Maass \& Anderson 1986). Fixed time slot rules allow farmers considerable certainty as to when they will receive water without an equivalent certainty about the quantity of water that will be available in the canal. When the order is based on a share system, simply owning land next to an irrigation system is not enough. A farmer must purchase one or more shares to irrigate for a particular time period. Fixed time allocation systems, which are frequently criticized as inefficient, do economize greatly on the amount of knowledge farmers have to have about the entire system and on monitoring costs. Spooner (1974) and Netting (1974) described long-lived irrigation systems in Iran and in Switzerland where there was perfect agreement on the order and time allotted to all farmers located on a segment of the system, but no one knew the entire sequence for the system as a whole.

Tang also found that many irrigation systems use different sets of rules depending on the availability of water. During the most abundant season, for example, irrigators may be authorized to take water whenever they need it. During a season when water is moderately available, farmers may use a rotation system where every farmer is authorized to take water for a fixed amount of time during the week based on the amount of land to be irrigated. During scarcity, the irrigation system may employ a special water distributor who is authorized to allocate water to those farmers who are growing crops authorized by the irrigation system and are most in need.

The diversity of rules devised by users greatly exceeds the limited choice rules recommended in textbook treatments of this problem. Appropriators thus cope with the commons by a wide variety of rules affecting the actions available to participants and thus their basic set of strategies. Given this wide diversity of rules, it is particularly noteworthy that rules assigning appropriators a right to a specific quantity of a resource are used so infrequently in inshore fisheries and irrigation systems. (They are used more frequently when allocating forest products where the quantity available, as well as the quantity harvested, are much easier to measure (Agrawal 1994)). To assign an appropriator a specific quantity of a resource unit requires that those making the assignment know the total available units. In water resources where there is storage of water from one season to another and reliable information about the quantity of water is available, such rules are more frequently utilized (Blomquist 1992; Schlager et al 1994).

\section{Using Payoff and Position Rules}

One way to reduce or redirect the appropriations made from a common-pool resource is to change payoff rules so as to add a penalty to actions that are prohibited. Many user groups also adopt norms that those who are rule breakers should be socially ostracized or shunned and individual appropriators tend to 
monitor each other's behavior rather intensively. Three broad types of payoff rules are used extensively in the field: (1) the imposition of a fine, (2) the loss of appropriation rights, and (3) incarceration. The severity of each of these types of sanctions can range from very low to very high and tends to start out on the low end of the scale. Inshore fisheries studied by Schlager relied heavily on shunning and other social norms and less on formal sanctions. Thirty-six of the 43 irrigation systems studied by Tang used one of these three rules and also relied on vigorous monitoring of each other's behavior and shunning of rule breakers. The seven systems that did not self-consciously punish rule infractions were all rated as having poor performance. Fines were most typically used (in 21 cases) and incarceration the least (in only 2 cases). Fines tend to be graduated depending on the seriousness of the infractions and the number of prior infractions. The fines used for a first or second offence tend to be very low.

Passing rules that impose costs is relatively simple. The real difficult task is monitoring behavior to ascertain if rules are being broken. Self-organized fisheries tend to rely on self-monitoring more than the creation of a formal position of guard. Most inshore fishers now use short-wave radios as a routine part of their day-to-day operations allowing a form of instant monitoring to occur. An official of a West Coast Indian tribe reports, for example, that "it is not uncommon to hear messages such as 'Did you see so-andso flying all that net?' over the short-wave frequency-a clear reference to a violation of specified gear limits" (cited in Singleton 1998:134). Given that most fishers will be listening to their short-wave radio, "such publicity is tantamount to creating a flashing neon sign over the boat of the offender. Such treatment might be proceeded or followed by a direct approach to the rule violator, advising him to resolve the problem. In some tribes, a group of fishermen might delegate themselves to speak to the person" (cited in Singleton 1998:134).

Among self-organizing forest governance systems, creating and supporting a position as guard is frequently essential since resource units are highly valuable and a few hours of stealth can generate substantial illicit income. Monitoring rule conformance among forest users by officially designated and paid guards may make the difference between a resource in good condition and one that has become degraded. In a study of 279 forest panchayats in the Kumaon region of India, Agrawal \& Yadama (1997) found that the number of months a guard was hired was the most important variable affecting forest conditions. The other variables that affected forest conditions included the number of meetings held by the forest council (a time when infractions are discussed) and the number of residents in the village.

It is evident from the analysis that the capacity of a forest council to monitor and impose sanctions on rule-breakers is paramount to maintaining the forest in good condition. Nor should the presence of a guard be taken simply as a formal mechanism that ensures greater protection. It is also an indication of the informal commitment of the panchayat and the village community to protect their forests. Hiring a guard costs money. The funds have to be generated within the village and earmarked for protection of the resource. If there was scant interest in protecting the forest, villagers would have little interest in setting aside the money necessary to hire a guard. (Agrawal \& Yadama 1997:455)

Whether irrigation systems create a formal position as guard depends both on the type of governance of the system and on its size. Of the 15 government-owned irrigation systems included in Tang (1992), 12 or 80 percent have established a position of guard. Stealing water was a problem on most governmentowned systems, but it was endemic on the three systems without guard. Of the 28 farmer-organized systems, 17 (61 percent) utilize the position of water distributor or guard. Of the 11 farmer-organized systems that do not employ a guard, farmers are vigilant enough in monitoring each other's activities on 5 systems (45 percent) that rule conformance is high. That means, of course, that self-monitoring is not high enough on the other 6 systems to support routine conformance with their own rules. A study by Romana de los Reyes (1980) of 51 communal irrigation systems in the Philippines illustrates the effect of size. Of the 30 systems that were less than 50 hectares, only 6 (20 percent) had established a position as guard; of the 11 systems that serve between 50 to 100 hectares, 5 (45 percent) had established guard; and 
of the 10 systems over 100 hectares, 7 (70 percent) had created guards. She also found that in a survey of over 600 farmers served by these communal irrigation systems, most farmers also patrolled their own canals even when they were patrolled by guards accountable to the farmers for distributing water. Further, the proportion of farmers who report patrolling the canals serving their farms increased to 80 percent on the largest self-organized systems compared to 60 percent on the smallest systems (for an analysis of both farmer organized and government systems in contemporary Philippines see Araral, 2005).

Boundary and choice rules also affect how easy or difficult it is to monitor activities and impose sanctions on rule infractions. Closing a forest or an inshore fishery for a substantial amount of time, for example, has multiple impacts. It protects particular plants or fish during critical growing periods and allows the entire system time to regenerate without disturbance. Further, during the closed season, rule infractions are highly obvious to anyone as any appropriator in the resource is almost certainly breaking the rules. Similarly, requiring appropriators to use a particular technology may reduce the pressure on the resource, help to solve conflicts among users of incompatible technologies, and also make it very easy to ascertain if rules are being followed. Many irrigation systems set up rotation systems so that only two persons need to monitor actions at any one time and thus keep monitoring costs lower than they would otherwise be. Changing payoff rules is the most direct way of coping with commons dilemmas. In many instances, dilemma games can be transformed into assurance games-a much easier situation to solve.

\section{Using Information, Scope, and Aggregation Rules}

These rules tend to be used in ways that complement changes in boundary, choice, payoff and position rules. Individual systems vary radically in regard to the mandatory information that they require. Many smaller and informal systems rely entirely on a voluntary exchange of information and on mutual monitoring. Where resource units are very valuable and the size of the group is larger, more and more requirements are added regarding the information that must be kept by appropriators or their officials. Scope rules are used to limit harvesting activities in some regions that are being treated as refugia. By not allowing any appropriation from these locations, the regenerative capacity of a system can be enhanced. Aggregation rules are used extensively in collective-choice processes and less extensively in operational settings, but one aggregation rule that is found in diverse systems is a requirement that harvesting activities be done in teams. This increases the opportunity for mutual monitoring and reduces the need to hire special guards.

It is important to note that we have not yet found any particular rules to have a statistically positive relationship to performance. The essential finding, however, is that the absence of any boundary or any choice rules is consistently associated with poor performance. Relying on only a single type of rule for an entire set of common-pool resources is also negatively related. As reported above, self-organized irrigation systems do tend on average to have performance levels higher than government-organized systems controlling for physical terrain but this increased performance level is not due to any specific rules or set of rules that we have yet been able to identify.

\section{$\underline{\text { Viewing Policies as Experiments }}$}

The search for rules that improve the outcomes obtained in commons dilemmas is an incredibly complex task whether undertaken by users or by government officials. It involves a potentially infinite combination of specific rules that could be adopted in any effort to match the rules to the attributes of the resource system itself. To ascertain whether one has found an optimal set of rules to improve the outcomes achieved in a single situation, one would need to analyze how diverse rules affect each of the seven components of such an action situation (or a game) and as a result, the likely effect of a reformed 
structure on incentives, strategies, and outcomes. Since there are multiple rules that affect each of the seven components, conducting such an analysis would be an incredibly time and resource-consuming process. For example, if only five changes in rules per component were considered, there would be $5^{7}$ or 75,525 different situations to analyze. This is a gross simplification, however, since some of the important rules used in field settings include more than 25 rules (in the case of boundary rules) and even over 100 variants (in the case of choice rules). Further, how these changes affect the outcomes achieved in a particular location depends on the biophysical characteristics of that location and the type of community relationships that already exist. No set of policy analysts (or even all of the game theorists in the world today) could ever have sufficient time or resources to analyze over 75,000 combinations of rule changes and resulting situations, let alone all of the variance in these situations due to biophysical differences.

Instead of assuming that designing rules that approach optimality, or even improve performance, is a relatively simple analytical task that can be undertaken by distant, objective analysts, we need to understand the policy design process as involving an effort to tinker with a large number of component parts (see Jacob 1977). Those who tinker with any tools-including rules-try to find combinations that work together more effectively than other combinations. Policy changes are experiments based on more or less informed expectations about potential outcomes and the distribution of these outcomes for participants across time and space (Campbell 1969, 1975). Whenever individuals agree to add a rule, change a rule, or adopt someone else's proposed rule set, they are conducting a policy experiment. Further, the complexity of the ever-changing biophysical world combined with the complexity of rule systems means that any proposed rule change faces a non-trivial probability of error.

When there is only a single authority for a large region, policymakers have to experiment simultaneously with all of the common-pool resources within their jurisdiction with each policy change. And, once a change has been made and implemented, further changes will not be made rapidly. The process of experimentation will usually be slow, and information about results may be contradictory and difficult to interpret (see Brock and Carpenter, 2007). Thus, an experiment that is based on erroneous data about one key structural variable or one false assumption about how actors will react, can lead to a very large disaster (see Wilson et al forthcoming). In any design process where there is substantial probability of error, having redundant teams of designers has repeatedly been shown to have considerable advantage (see Landau 1969, 1973; Bendor 1985).

For example, let us imagine a series of inshore fisheries located along the coast of a region and posit that every policy change has a probability of failure of $1 / 10$. If the region were regulated by a single governing agency, one out of ten policy changes would be failures for the entire region. If designing rules were delegated to three genuinely independent authorities, on the other hand, each of these authorities would still face a failure rate of one out of ten. The probability that a failure would simultaneously occur along the entire coast, however, would be reduced from $1 / 10$ to $1 / 10^{3}$ or $1 / 1000$. On a coast with many more relatively separable inshore fisheries, the likelihood of a coastal-wide failure is reduced still more. Of course, the failure rate for such design tasks can itself not be known, but the positive effect of parallel, redundant design teams each trying to find the best combination of rules does not depend on any particular error rate. The important point is: If the systems are relatively separable, allocating responsibility for experimenting with rules will not avoid failure, but will drastically reduce the probability of immense failures for an entire region.

\section{The Advantages of Polycentric Resource Governance Systems}

The last major task to be undertaken in this paper is to discuss why a series of nested but relatively autonomous, self-organized, resource governance systems may do a better job in policy experimentation than a single central authority. A polycentric system is one where citizens are able to organize not just 
one but multiple governing authorities at differing scales (see V. Ostrom et al 1961; V. Ostrom 1987, 1991, 1997). Thus, a polycentric system would have some units at a smaller scale corresponding to the size of the basic common-pool resources in the system. Among the advantages of authorizing the users of smaller-scale common-pool resources to adopt policies regulating the use of common-pool resources are:

- Local knowledge. Appropriators who have lived and appropriated from a resource system over a long period of time have developed relatively accurate mental models of how the biophysical system itself operates, since the very success of their appropriation efforts depends on such knowledge. They also know others living in the area and what norms of behavior are considered appropriate in what circumstances.

- Inclusion of trustworthy participants. Appropriators can devise rules that increase the probability that others will be trustworthy and use reciprocity. This lowers the cost of relying entirely on formal sanctions and paying for extensive guarding.

- Reliance on disaggregated knowledge. Feedback about how the resource system responds to changes in actions of appropriators is provided in a disaggregated way. Fishers are aware, for example, if the size and species distribution of their own catch is changing over time and tend to discuss the size of their catch with other fishers. Irrigators learn whether a particular rotation system allows most farmers to grow the crops they most prefer by examining the resulting productivity of specific fields or talking with others about yields at a weekly market.

- Better adapted rules. Given the above, appropriators are more likely to craft rules that are better adapted to each of the local common-pool resources than any general system of rules.

- Lower enforcement costs. Since local appropriators have to bear the cost of monitoring, they are more likely than central authorities to craft rules that make infractions obvious to other appropriators so that monitoring costs are lower. Further, by creating rules that are seen as legitimate, rule conformance will tend to be higher.

- Redundancy. The probability of failure throughout a large region is greatly reduced by the establishment of parallel systems of rule making, interpretation, and enforcement (see Ostrom, 2005 for further elaboration of these elements).

There are, of course, limits to all ways of organizing the governance of common-pool resources. Among the limits of a highly decentralized system are:

- Some appropriators will not organize. While the evidence from the field is that many local appropriators do invest considerable time and energy into their own regulatory efforts, other groups of appropriators do not do so. There appear to be many reasons for why some groups do not organize including the presence of low-cost alternative sources of income and thus a reduced dependency on the resource, considerable conflict among appropriators along multiple dimensions, lack of leadership, and fear of having their efforts overturned by outside authorities.

- Some self-organized efforts will fail. Given the complexity of the task involved in designing rules, some groups will select combinations of rules that generate failure instead of success. They may be unable to adapt rapidly enough to avoid the collapse of a resource system.

- Local tyrannies. Not all self-organized resource governance systems will be organized democratically or rely on the input of most appropriators. Some will be dominated by a local leader or a power elite who only change rules that they think will advantage them still further. 
This problem is accentuated in locations where the cost of exit is particularly high and reduced where appropriators can leave when local decision makers are not responsible to a wide set of interests.

- Stagnation. Where local ecological systems are characterized by considerable variance, experimentation can produce severe and unexpected results leading appropriators to cling to systems that have worked relatively well in the past and stop innovating long before they have developed rules likely to lead to better outcomes.

- Inappropriate discrimination. The use of identity tags is frequently an essential method for increasing the level of trust and rule conformance. Tags based on ascribed characteristics can, however, be the basis of excluding some individuals from access to sources of productive endeavor that has nothing to do with their trustworthiness.

- Limited access to scientific information. While time and place information may be extensively developed and used, local groups may not have access to scientific knowledge concerning the type of resource system involved.

- Conflict among appropriators. Without access to an external set of conflict-resolution mechanisms, conflict within and across common-pool resource systems can escalate and provoke physical violence. Two or more groups may claim the same territory and may continue to make raids on one another over a very long period of time.

- Inability to cope with larger-scale common-pool resources. Without access to some larger-scale jurisdiction, local appropriators may have substantial difficulties regulating only a part of a larger-scale common-pool resource. They may not be able to exclude others who refused to abide by the rules that a local group would prefer to use. Given this, local appropriators have no incentives to restrict their own use and watch others take away all of the valued resource units that they have not appropriated.

Many of the capabilities of a parallel adaptive system can be retained in a polycentric governance system. Each unit may exercise considerable independence to make and enforce rules within a circumscribed scope of authority for a specified geographical area. In a polycentric system, some units are generalpurpose governments while others may be highly specialized. Self-organized resource governance systems, in such a system, may be special districts, private associations, or parts of a local government. These are nested in several levels of general-purpose governments that also provide civil, equity, as well as criminal courts.

In a polycentric system, the users of each common-pool resource would have some authority to make at least some of the rules related to how that particular resource will be utilized, and thus would achieve most of the advantages of utilizing local knowledge, and the redundancy and rapidity of a trial and error learning process. On the other hand, problems associated with local tyrannies and inappropriate discrimination can be addressed in larger, general-purpose governmental units who are responsible for protecting the rights of all citizens and for the oversight of appropriate exercises of authority within smaller units of government. It is also possible to make a more effective blend of scientific information with local knowledge where major universities and research stations are located in larger units but have a responsibility to relate recent scientific findings to multiple smaller units within their region. Because polycentric systems have overlapping units, information about what has worked well in one setting can be transmitted to others who may try it out in their settings. Associations of local, resource governance units can be encouraged to speed up the exchange of information about relevant local conditions and about 
policy experiments that have proved particularly successful. And, when small systems fail, there are larger systems to call upon-and vice versa.

Polycentric systems are themselves complex, adaptive systems without one central authority always dominating all of the others. Thus, there is no guarantee that such systems will find the optimal combination of rules at diverse levels that are optimal for any particular environment. In fact, one should expect that all governance systems will be operating at less than optimal levels given the immense difficulty of fine-tuning any very complex, multitiered system.

Trying to find better ways of overcoming the potential tragedies of the commons is never easy and never finished. With strong empirical evidence that those dependant on small to medium-size commonpool resources are not forever trapped in situations that will only get worse over time, we need to recognize that governance is frequently an adaptive process involving multiple actors at diverse levels. Such systems look terribly messy and hard to understand. The scholars' love of tidiness needs to be resisted. Instead, we need to develop better theories of complex adaptive systems, particularly those that have proved themselves able to utilize renewable natural resources sustainably over time.

Overcoming a commons dilemma is always a struggle (Dietz, Ostrom, and Stern 2003). 
Table 1 Attributes and conditions used in boundary rules to define who is authorized to appropriate from a common-pool resource

\begin{tabular}{lll}
\hline & Attributes & Conditions \\
\hline $\begin{array}{l}\text { Residency or } \\
\text { Membership }\end{array}$ & $\begin{array}{l}\text { Personal } \\
\text { characteristics } \\
\text { National }\end{array}$ & Relationship with resource \\
$\begin{array}{l}\text { Ascribed } \\
\text { Local community }\end{array}$ & Age & \\
$\begin{array}{l}\text { Organization } \\
\text { (e.g., co-op) }\end{array}$ & Clan & Use of specified technology \\
& Class & Continued use of resource \\
& Ethnicity & \\
Gender & Race & Long-term rights based on: \\
& Ownership of a proportion of annual \\
& flow of resource units \\
& Acquired & Ownership of land \\
Education level & Ownership of nonland asset (e.g., berth) \\
Skill test & Ownership of shares in a private \\
& organization \\
& Ownership of a share of the resource \\
& system \\
& & Temporary use-rights acquired through: \\
& Auction \\
& Per-use fee \\
& Licenses \\
& Lottery \\
& Registration \\
& Seasonal fees \\
&
\end{tabular}

Adapted from E. Ostrom (2005: chap. 8, table 8.1). 
Table 2 Types of choice rules

Allocation formula for appropriation rights

Percentage of total available units per period

Quantity of resource units per period

Location

Time slot

Rotational order

Appropriate only during open seasons

Appropriate only resource units meeting criteria

Appropriate whenever and wherever
Basis for allocation formula

Amount of land held

Amount of historical use

Location of appropriator

Quantity of shares of resource owned

Proportion of resource flow owned

Purchase of periodic rights at auction

Rights acquired through periodic lottery

Technology used

License issued by a governmental authority

Equal division to all appropriators

Needs of appropriators (e.g. type of crop)

Ascribed characteristic of appropriator

Membership in organization

Assessment of resource condition

Adapted from E. Ostrom (2005: chap. 8, table 8). 


\section{References}

Acheson JM, Wilson JA, Steneck RS. 1998. Managing chaotic fisheries. In Linking Social and Ecological Systems. Management Practices and Social Mechanisms for Building Resilience, ed. F Berkes, C Folke, 390-413. Cambridge, MA: Cambridge Univ. Press

Acheson, JM, Gardner R. 2005. Spatial strategies and territoriality in the Maine lobster industry. Rationality and Society 17(3): 309-341.

Agrawal A. 1994. Rules, rule making, and rule breaking: Examining the fit between rule systems and resource use. In Rules, Games, and Common-Pool Resources, ed. E Ostrom, R Gardner, JM Walker, 267-82. Ann Arbor: Univ. of Michigan Press

Agrawal A, Yadama GN. 1997. How do local institutions mediate market and population pressures on resources? Forest panchayats in Kumaon, India. Development and Change 28(3):435-65

Anderson LG. 1986. The Economics of Fisheries Management. Rev. ed. Baltimore, MD: Johns Hopkins Univ. Press

Anderson LG. 1992. Consideration of the potential use of individual transferable quotas in U.S. fisheries. The National ITQ Study Report 1:1-71

Anderson, C., Putterman, L., 2005. Do non-strategic sanctions obey the law of demand? The demand for punishment in the voluntary contribution mechanism. Games and Economic Behavior 54, 1-24.

Araral, E. 2005. "Bureaucratic Incentives, Path Dependence, and Foreign Aid: An Empirical Institutional Analysis of Irrigation in the Philippines.” Policy Sciences 38(2-3) (September): 131-157.

Baland J-M, Platteau J-P. 1996. Halting Degradation of Natural Resources: Is There a Role for Rural Communities? Oxford: Clarendon Press

Bardhan, PK. 2000. "Irrigation and Cooperation: An Empirical Analysis of 48 Irrigation Communities in South India.” Economic Development and Cultural Change 48(4) (July): 847-65.

Bendor JB. 1985. Parallel Systems. Redundancy in Government. Berkeley: Univ. of California Press

Bendor JB. 1987. In good times and bad: Reciprocity in an uncertain world. American Journal of Political Science 31(3): 531-58

Bendor JB, Mookherjee D. 1990. Norms, third-party sanctions, and cooperation. Journal of Law, Economics, and Organization 6:33-63

Berkes F, ed. 1989. Common Property Resources. Ecology and Community-Based Sustainable Development. London: Belhaven Press

Berkes, F. forthcoming 2007. "Community-based conservation in a globalized world" in Proceedings of the National Academy of Sciences (USA)

Berkes F, Feeny D, McCay BJ, Acheson JM. 1989. The benefits of the commons. Nature 340(6229): 91-93 
Blomquist W. 1992. Dividing the Waters: Governing Groundwater in Southern California. San Francisco, CA: ICS Press

Brock S., Carpenter S, forthcoming 2007. "Panaceas and Diversification of Environmental Policy," Proceedings of the National Academy of Science (USA)

Bromley DW, Feeny D, McKean MA, Peters P, Gilles J, et al, eds. 1992. Making the Commons Work: Theory, Practice, and Policy. San Francisco, CA: ICS Press

Campbell DT. 1969. Reforms as experiments. American Psychologist 24(4): 409-29

Campbell DT. 1975. On the conflicts between biological and social evolution and between psychology and moral tradition. American Psychologist 30(11): 1103-26

Cardenas, JC. 2001. "How Do Groups Solve Local Commons Dilemmas? Lessons from Experimental Economics in the Field". Environment, Development and Sustainability, Vol. 2, Nos. 3-4: 305-322. Kluwer Academic Publishers. 2001.

Cardenas, JC, Stranlund, J and Willis, CE. 2000. "Local Environmental Control and Institutional Crowding-out". World Development, October, Vol 28, No. 10. pp. 1719-1733.

Carpenter, J., Matthews, P., Ong'ong'a, O., 2004. Why punish? Social reciprocity and the enforcement of prosocial norms. Journal of Evolutionary Economics 14, 407-429.

Casari, M and CR Plott. 2003. "Decentralized Management of Common Property Resources: Experiments with a Centuries-Old Institution.” Journal of Economic Behavior and Organization 51:217-47.

Copes P. 1986. A critical review of the individual quota as a device in fisheries management. Land Economics 62(3):278-91

de los Reyes RP. 1980. Managing Communal Gravity Systems: Farmers' Approaches and Implications for Program Planning. Quezon City, Philippines: Ateneo de Manila University, Institute of Philippine Culture

Dietz, Thomas, Elinor Ostrom, and Paul Stern. 2003. “The Struggle to Govern the Commons.” Science 302(5652): 1907-1912.

Elster J. 1989. The Cement of Society. A Study of Social Order. Cambridge: Cambridge Univ. Press

Fehr, E., Gächter, S., 2000. Cooperation and punishment in public goods experiments. American Economic Review 90, 980-994.

Fortmann L, Bruce JW. 1988. Whose Trees? Proprietary Dimensions of Forestry. Boulder, CO: Westview Press

Frohlich N, Oppenheimer JA, Eavey CL. 1987. Choices of principles of distributive justice in experimental groups. American Journal of Political Science 31(3):606-36

Gautam, AP \& Shivakoti, GP. 2005. "Conditions for Successful Local Collective Action in Forestry: Some Evidence from the Hills of Nepal.” Society and Natural Resources 18(2):153-171. 
Gibson C, McKean MA, Ostrom E. 1998. Forest Resources and Institutions. Forests, Trees and People Programme, Working Paper no. 3. Rome, Italy: Food and Agriculture Organization of the United Nations

Gibson, C, Williams JT and Ostrom E. 2005. "Local Enforcement and Better Forests.” World Development 33(2) (February): 273-284.

Gordon HS. 1954. The economic theory of a common property resource: The fishery. Journal of Political Economy 62:124-42

Guillet, DW. 1992a. "Comparative Irrigation Studies: The Órbigo Valley of Spain and the Colca Valley of Perú.” Polígonos 2:141-50.

Guillet, DW. 1992b. Covering Ground: Communal Water Management and the State in the Peruvian Highlands. Ann Arbor: University of Michigan Press.

Gupta, R \& Tiwari S 2002. "At the Crossroads: Continuity and Change in the Traditional Irrigation Practices of Ladakh.” Paper presented at "The Commons in an Age of Globalization," the Ninth Conference of the International Association for the Study of Common Property, Victoria Falls, Zimbabwe.

Hardin G. 1968. The tragedy of the commons. Science 162:1243-48

Hayes TM (2006) Parks, people, and forest protection: an institutional assessment of the effectiveness of protected areas. World Development 34(12):2064-2075

Hayes, TM \& Ostrom, E. 2005. “Conserving the World’s Forests: Are Protected Areas the Only Way?” Indiana Law Review 38(3):595-617.

Jacob F. 1977. Evolution and tinkering. Science 196(4295) (June 10):1161-66

Lam WF. 1998. Governing Irrigation Systems in Nepal: Institutions, Infrastructure, and Collective Action. Oakland, CA: ICS Press

Landau M. 1969. Redundancy, rationality, and the problem of duplication and overlap. Public Administration Review 29(4):346-58

Landau M. 1973. Federalism, redundancy, and system reliability. Publius 3(2):173-96

Lansing JS. 1991. Priests and Programmers. Technologies of Power in the Engineered Landscape of Bali. Princeton, NJ: Princeton Univ. Press

Lansing JS, Kremer JN. 1994. Emergent properties of Balinese water temple networks: Co-adaption on a rugged fitness landscape. In Artificial Life III. Studies in the Sciences of Complexity, Vol. XVII, ed. CG Langton, 201-23. Reading, MA: Addison-Wesley

Levi M. 1988. Of Rule and Revenue. Berkeley: Univ. of California Press

Maass A, Anderson RL. 1986. . . a and the Desert Shall Rejoice: Conflict, Growth, and Justice in Arid Environments. Malabar, FL: RE Krieger 
McCay BJ, Acheson JM. 1987. The Question of the Commons: The Culture and Ecology of Communal Resources. Tucson: Univ. of Arizona Press

Meinzin-Dick, R. forthcoming 2007. "Beyond panaceas in water institutions," Proceedings of the National Academy of Sciences (USA).

Morrow CE, Hull RW. 1996. Donor-initiated common-pool resource institutions: The case of the Yanesha forestry cooperative. World Development 24(10):1641-57

Nagendra H, Karna, B. \& Karmacharya M. 2005. "Examining Institutional Change: Social Conflict in Nepal’s Leasehold Forestry Programme.” Conservation and Society 3(1):72-91.

Netting RMcC. 1974. The system nobody knows: Village irrigation in the Swiss Alps. In Irrigation's Impact on Society, ed. TE Downing, M Gibson, 67-75. Tucson: Univ. of Arizona Press

Netting RMcC. 1993. Smallholders, Householders: Farm Families and the Ecology of Intensive, Sustainable Agriculture. Stanford, CA: Stanford Univ. Press

Ostrom E. 1990. Governing the Commons: The Evolution of Institutions for Collective Action. New York: Cambridge Univ. Press

Ostrom E. 1998. A behavioral approach to the rational choice theory of collective action. American Political Science Review 92(1):1-22

Ostrom, E, 2001. "Reformulating the Commons.” In Protecting the Commons: A Framework for Resource Management in the Americas, ed. Joanna Burger, Elinor Ostrom, Richard B. Norgaard, David Policansky, and Bernard D. Goldstein, 17-41. Washington, D.C.: Island Press.

Ostrom, E. 2005. Understanding Institutional Diversity. Princeton: Princeton University Press.

Ostrom E, Gardner R, Walker JM. 1994. Rules, Games, and Common-Pool Resources. Ann Arbor: Univ. of Michigan Press

Ostrom E, Walker JM. 1997. Neither markets nor states: Linking transformation processes in collective action arenas. In Perspectives on Public Choice: A Handbook, ed. DC Mueller, 35-72. Cambridge: Cambridge Univ. Press

Ostrom E, Walker JM, Gardner R. 1992. Covenants with and without a sword: Self-governance is possible. American Political Science Review 86(2):404-17

Ostrom E, Nagendra H. 2006. Insights on linking forests, trees, and people from the air, on the ground, and in the laboratory. Proceedings of the National Academy of Sciences (USA) 103(51): 1922419231

Ostrom V. 1987. The Political Theory of a Compound Republic: Designing the American Experiment. 2d rev. ed. San Francisco, CA: ICS Press

Ostrom V. 1991. The Meaning of American Federalism: Constituting a Self-Governing Society. San Francisco, CA: ICS Press 
Ostrom V. 1997. The Meaning of Democracy and the Vulnerability of Democracies: A Response to Tocqueville's Challenge. Ann Arbor: Univ. of Michigan Press

Ostrom V, Tiebout CM, Warren R. 1961. The organization of government in metropolitan areas: A theoretical inquiry. American Political Science Review 55:831-42

Palanisami K. 1982. Managing tank irrigation systems: Basic issues and implications for improvement. Presented at workshop on Tank Irrigation: Problems and Prospects

Repetto R. 1986. Skimming the water: Rent-seeking and the performance of public irrigation systems. Research report no. 4. Washington, DC: World Resources Institute

Rocco E, Warglein M. 1995. Computer mediated communication and the emergence of 'electronic opportunism'. Working paper RCC\#13659. Universita degli Studi di Venezia

Schlager E. 1990. Model specification and policy analysis: The governance of coastal fisheries. Ph.D. diss., Indiana University, Bloomington.

Schlager E. 1994. Fishers' institutional responses to common-pool resource dilemmas. In Rules, Games, and Common-Pool Resources, ed. E Ostrom, R Gardner, JM Walker, 247-65. Ann Arbor: Univ. of Michigan Press

Schlager E, Blomquist W, Tang SY. 1994. Mobile flows, storage, and self-organized institutions for governing common-pool resources. Land Economics 70(3):294-317

Scott AD. 1955. The fishery: The objectives of sole ownership. Journal of Political Economy 63:116-24

Sherman K, Laughlin T, eds. 1992. NOAA Technical Memorandum NMFS-f/NEC 91. The Large Marine Ecosystem (LME) Concept and Its Application to Regional Marine Resource Management. Woods Hole: Northeast Fisheries Science Center

Shivakoti, G. Ostrom E. eds. 2002. Improving Irrigation Governance and Management in Nepal. Oakland, CA: ICS Press.

Singleton S. 1998. Constructing Cooperation. The Evolution of Institutions of Co-management in Pacific Northwest Salmon Fisheries. Ann Arbor: Univ. of Michigan Press

Singleton S, Taylor M. 1992. Common property economics: A general theory and land use applications. Journal of Theoretical Politics 4:309-24

Spooner B. 1974. Irrigation and society: The Iranian plateau. In Irrigation's Impact on Society, ed. TE Downing, M Gibson, 43-57. Tucson: Univ. of Arizona Press

Tang SY. 1992. Institutions and Collective Action: Self-Governance in Irrigation. San Francisco, CA: ICS Press

Tang SY. 1994. Institutions and performance in irrigation systems. In Rules, Games, and Common-Pool Resources, ed. E Ostrom, R Gardner, JM Walker, 225-45. Ann Arbor: Univ. of Michigan Press

Taylor M. 1982. Community, Anarchy, and Liberty. New York: Cambridge Univ. Press 
Trawick, PB. 2001. "Successfully Governing the Commons: Principles of Social Organization in an Andean Irrigation System.” Human Ecology 29(1):1-25.

Weinstein, MS. 2000. "Pieces of the Puzzle: Solutions for Community-Based Fisheries Management from Native Canadians, Japanese Cooperatives, and Common Property Researchers.” Georgetown International Environmental Law Review 12(2):375-412.

Weissing FJ, Ostrom E. 1991a. Crime and punishment: Further reflections on the counterintuitive results of mixed equilibria games. Journal of Theoretical Politics 3(3):343-50

Weissing FJ, Ostrom E. 1991b. Irrigation institutions and the games irrigators play: Rule enforcement without guards. In Game Equilibrium Models II: Methods, Morals, and Markets, ed. R Selten, 188-262. Berlin: Springer-Verlag

Wilson JA, Acheson JM, Kleban M, Metcalfe M. 1994. Chaos, complexity, and community management of fisheries. Marine Policy 18:291-305

Wilson JA, French J, Kleban P, McKay SR, Townsend, R. 1991. Chaotic dynamics in a multiple species fishery: A model of community predation. Ecological Modelling 58:303-22

Wilson JA, Yan L, Wilson C. 2007. Modeling the precursors of governance in the Maine lobster fishery. Paper in forthcoming PNAS 